\title{
O SUJEITO-ARTISTA E SEUS DESDOBRAMENTOS: UMA ANÁLISE DISCURSIVA DO PROCESSO CRIATIVO DO LIVRO DE IMAGENS
}

\section{THE SUBJECT-ARTIST AND ITS UNFOLDINGS: A DISCOURSE ANALYSIS OF THE CREATIVE PROCESS OF THE PICTURE BOOK}

\section{Carolina Fernandes \\ Universidade Federal do Pampa}

RESUMO: Influenciado pelo Movimento Artes e Ofícios, o livro de imagens teve boa aceitação no mercado editorial brasileiro. Além do sucesso pelo trabalho artístico visual, os ilustradores almejam um lugar no campo literário para suas obras. Mas pode o livro de imagem instaurar-se no domínio do saber literário? Este artigo visa discutir o processo criativo do livro de imagens à luz da Análise de Discurso de linha Francesa, investigando a constituição do sujeito produtor deste livro e sua relação com a escrita. Para isso, elegemos como objeto de análise os seguintes livros: Espelho, de Suzy Lee e Cena de Rua, de Angela Lago.

PALAVRAS-CHAVE: Livros de imagens. Formação discursiva. Artes. Literatura. Escrita. Análise de Discurso.

ABSTRACT: Influenced by the Arts and Crafts Movements, the picture book was well received in the Brazilian publishing market.

\footnotetext{
* É Doutora em Letras pela Universidade Federal do Rio Grande do Sul (UFRGS) e mestre em estudos da Linguagem pela mesma instituição. É professora Adjunta do Curso de Letras na Universidade Federal do Pampa (Unipampa) no campus de Bagé. Bagé, Rio Grande do Sul, Brasil. E-mail: carolinafernandes@unipampa.edu.br.
} 
Besides the success at the visual artwork, illustrators crave a place in the literary field for their works. But can the picture book establish itself in the literary knowledge field? This paper aims to discuss the creative process of the picture book supported by the French Discourse Analysis, exploring the constitution of the producing subject of this book and its relation to the writing. For that, we chose as the object of analysis the following books: Espelho (Mirror), by Suzy Lee and Cena de Rua, by Angela Lago.

KEYWORDS: Picture books. Discursive formation. Arts. Literature. Writing. Discourse Analysis. 


\section{CONSIDERAÇÕES INICIAIS}

O livro de imagens, ou picture book (livro-pintura), surgiu com o movimento Artes e Ofícios de inspiração pré-rafaelista, que considera o livro um objeto físico trabalhado em toda sua composição material e textual. Esses livros possuem linguagem verbal escassa ou quase nula (salvo o título). É, portanto, a partir da linguagem visual que se desenvolve todo o fio narrativo. Na conjuntura social do Brasil, o livro de imagem surgiu com a pretensão lúdica e estética, visto que foi um artista plástico, Juarez Machado, quem produziu, em 1968, o primeiro livro escrito somente com imagens: Ida e Volta. A narrativa visual trata da rotina de um homem que é representado apenas por suas pegadas. A obra é manipulável e mantém o fio narrativo da capa à contracapa, apresentando o livro como um objeto de arte.

A partir de então, os livros de imagens conquistaram o mercado editorial brasileiro que ampliou consideravelmente sua produção. Em 1982, a Fundação Nacional do Livro Infantil e Juvenil (FNLIJ) reconheceu a função do ilustrador como escritor e incluiu na sua premiação anual a categoria de Melhor Livro de Imagens. Além disso, exposições pelo Brasil e pelo mundo dão visibilidade a esses trabalhos, expondo os originais como obras de arte. 
A valorização desse tipo de obra deve-se, primeiramente, à sua qualidade técnica e artística de produção e reprodução de imagens em sequência. Contribuem também para isso a especificidade desses livros que é a produção de um fio narrativo construído pela ordenação do significante visual em formato de livro, o que faz com que a admiração por esse trabalho ultrapasse os campos das artes e da literatura infantil.

Nesses livros, o efeito literário da palavra é suprimido pelo encantamento das imagens. Cala-se a palavra e vê-se reinar a imagem em sua plena poesia. Neste artigo, observamos que a discursividade do livro de imagens é composta por saberes provenientes das artes visuais, da criação literária e das técnicas de reprodução de imagem. É entrecruzado nesses saberes que vai se constituir o produtor desse tipo de texto. Assim, faz-se necessária uma primeira discussão acerca dos conceitos de escrita, linguagem e sujeito desenvolvidos sob a base teórica da Análise de Discurso, o que permite observar a linguagem enquanto materialidade discursiva e o sujeito como cindido em posições-sujeito.

Com essa retomada do percurso das noções de escrita e de sujeito na teoria que ancora as análises, é possível compreender o modo de constituição do sujeito produtor dos livros de imagens e como essa constituição influi no processo criativo da textualização desses livros. A análise da constituição desse sujeito dividido entre as Artes Visuais e a Arte Literária possibilita a compreensão do gesto de escrita do livro de imagens como o resultado de dois processos interligados: o processo discursivo de produção de sentidos e o processo criativo de produção da arte. Para investigar a constituição dessa subjetividade dividida entre dois domínios de saber, vamos analisar o processo criativo dos livros Espelho, de Suzy Lee (2010), e Cena de Rua, de Angela Lago (1994), bem como recortes de sequências discursivas de falas de ilustradores que nos ajudam a compreender sua relação com a produção artístico-literária. 


\section{REVENDO OS CONCEITOS DE ESCRITA E LINGUAGEM EM RELAÇÃO AO SIGNIFICANTE VISUAL}

Escrita e leitura são conceitos intrinsecamente ligados, sendo que uma é o avesso da outra, isto é, não teríamos o que ler se não houvesse nada escrito, e mesmo a escrita, como retrata a paleografia, nasce da leitura. É lendo os traços ou rastros deixados pelos animais no solo que o homem primitivo começa a interpretar sinais gráficos. Várias pegadas podiam representar um animal específico e indicar a direção para onde aquele animal teria ido. É dessa forma que Barthes e Marty (1987, p. 32) concluem que o "ato de escrever tem origem no ato de ler" e esse ato é estritamente visual. Assim, os autores também entendem que a sociedade começou a estruturar-se em torno do visual. A imagem está, portanto, na origem dos processos de escrita e de leitura. Etimologicamente, escrita significa "gravar, fazer uma marca, traçar linhas" (BARTHES; MARTY, 1987), a evolução do processo de "fazer marcas" passou por algumas etapas até chegar na escrita que conhecemos hoje. Conta Higounet (2003, p. 11) que o processo de fixação da escrita como "meio de expressão permanente" passou de uma representação sintética e analítica até chegar à representação fonética, baseada na convenção gráfica dos sons da fala. A escrita fonética surge pela decomposição da fala em unidades menores que representavam os fonemas da linguagem articulada. Desse modo, a memorização dessas unidades menores permitia a formação de infinitas palavras e infinitas frases. A linguagem oral recebe para cada som uma representação visual, sendo que, como observa Martins (1957, p. 302), "a própria impressão de letras não passa, no fundo, de um processo de gravura”. Eis a formação da escrita fonética que se desenvolveu em dois grandes sistemas: o alfabético e o silábico.

Como percebemos, a representação visual da sonoridade da língua é apagada da história da escrita produzindo um imaginário de que a fala é traduzida pela grafia. Uma é apenas a imagem da outra dada por pura convenção, no entanto recebe prestígio social e se coloca como um sistema de comunicação que, até mesmo, dita as normas para a expressão oral, gerenciando a gramática normativa ao prescrever as regras do "bom uso" da língua. Assim, a construção histórica do conceito de escrita passa a determinar que, 
para uma forma significante ser considerada escrita, "é preciso inicialmente um conjunto de sinais que possua um sentido estabelecido de antemão por uma comunidade social e que seja por ela utilizado e em seguida é preciso que esses sinais permitam gravar e reproduzir uma frase falada" (FÉVRIER apud HIGOUNET, 2003, p. 11). O imaginário social relaciona, então, a fala à escrita, fazendo com que esta represente a imobilização da linguagem articulada. A escrita, como dito anteriormente, não nasce do fato auditivo e sim do visual, "sua característica fundamental é o isolamento de um traço significante através da grafia”, dizem Barthes e Marty (1987, p. 32). Portanto, não há relação natural entre a língua falada e a língua escrita, trata-se de pura convenção que liga uma impressão visual a uma impressão acústica, segundo os termos saussurianos (SAUSSURE, 2006, p. 35). O ato gráfico trata-se, portanto, do reconhecimento de uma marca visual e não de uma transcrição da fala.

Esse resgate histórico serve à perspectiva da Análise de Discurso, uma vez que, para essa teoria, a linguagem não é sistema de signos adicionado à fala, nem representação do pensamento, mas é materialidade discursiva, isto é, é a forma material que assume os "efeitos de sentidos" (definição de Pêcheux dado ao conceito de discurso, (PÊCHEUX, 1997, p. 82), que são produzidos na indissociabilidade entre língua e exterioridade. Além disso, a forma material que o discurso pode tomar não se restringe à linguagem verbal, ela pode ser visual ou sonora. Nesse sentido, preferimos adotar o termo materialidade significante cunhado por Lagazzi-Rodrigues (2009) que designa a forma material do discurso, seu corpo. E o "corpo é o lugar material em que acontece a significação, lugar de inscrição, manifestação do grafismo. Pintura. Texto" (ORLANDI, 2008, p. 205).

Nessa perspectiva, o conceito de texto para a AD admite a forma visual como possibilidade de textualização do discurso. E para analisarmos o texto visual, é importante considerar sua estrutura equívoca e opaca. Assim como a língua não é transparente, literal e unívoca, a imagem enquanto materialidade discursiva também não é, como já assinalava Pêcheux (1999, p. 55):

A questão da imagem encontra assim a análise de discurso por um outro viés: não mais a imagem legível 
na transparência, porque um discurso a atravessa e a constitui, mas a imagem opaca e muda, quer dizer, aquela da qual a memória "perdeu” o trajeto de leitura (ela perdeu assim um trajeto que jamais deteve em suas inscrições).

A imagem não carrega em si um trajeto predeterminado de sua leitura. É materialidade desviante que só encontra no sujeito uma paragem. Além disso, a opacidade do significante visual burla o olhar do leitor, provoca-lhe sentidos outros que o enganam muitas vezes. É como diz Lacan (2008, p. 104): "o olho é feito para não ver" e usa a expressão "jogo de trompe l'oeil", o jogo de engano do olho, a trapaça da linguagem visual, que é exemplificada no gesto de interpretação da imagem da personagem de Cena de Rua, de Angela Lago, trazida logo a seguir:

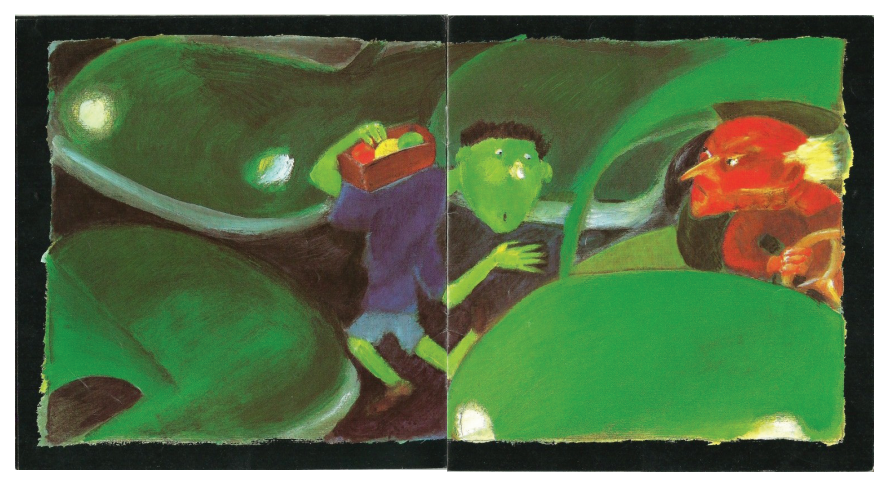

Imagem 1: Páginas 6 e 7 do livro Cena de Rua, de Angela Lago, Editora RHJ (1994).

O menino que vive na rua e trabalha no farol para sobreviver é visto da seguinte forma em uma das leituras dessa obra por aluno do Ensino Fundamental: "Era uma vez um menino verde, mas que era negro". A imagem do menino pintado com a cor verde não é transparente, pois a memória do dizer recupera, do interdiscurso, a imagem dos meninos da "vida real" que ficam nos faróis, em sua maioria, negros, o que também traz à tona, por meio da memória discursiva, a escravidão e a situação do negro em um país ex-colônia. É essa imagem do negro com toda sua historicidade que vem 
ressoar na leitura de Cena de Rua (1994) e turva a imagem visível do livro. Há um jogo aqui entre visibilidade e invisibilidade, em que o invisível atravessa o visível com sentidos outros que só são possíveis porque a imagem é materialidade histórica e ideológica. Cabe ressaltar que a noção de ideologia é percebida aqui como "sentidos em certa direção" (ORLANDI, 1996b, p. 36) que produzem um imaginário necessário à evidência dos sentidos.

Como podemos observar, o conceito de materialidade significante comporta diversas formas de linguagem e de textualidade, o que nos permite falar em uma escrita visual, além da escrita verbal. Logo, escrita e leitura já são vistas como processos discursivos desde a origem do conceito de discurso como efeito de sentidos entre sujeitos. Nessa acepção, a interpretação se torna atividade primeira na análise de discurso. O texto é percebido como a unidade de análise que dá acesso ao discurso por meio do "gesto interpretativo". Tomar um "gesto" de interpretação significa inscrever-se no discurso durante o processo de significação, considerando a constituição ideológica dos sujeitos, a historicidade da linguagem e sua exterioridade.

\section{UMA INCURSÃO PELA NOÇÃO DE SUJEITO DISCURSIVO}

Como explicitado anteriormente, a Análise do Discurso (AD) reflete sobre a linguagem e os processos que a envolve pelo viés do sentido. É por este viés que se interroga sobre a relação existente entre os atos discursivos de leitura e escrita. A leitura, nesta perspectiva, "suporta um jogo de efeitos de sentido entre autor e leitor" (INDURSKY, 2010, p. 171), resultando, dessa forma, em uma "interlocução discursiva" estabelecida entre sujeitos historicamente determinados. O sujeito é, nesse aspecto, um efeito discursivo e se constitui por meio da torção entre a ideologia, a linguagem e o inconsciente. O funcionamento ideológico desse conceito no processo discursivo é percebido por Pêcheux (1997, p. 82) já em sua Análise Automática do Discurso de 1969 (a AAD69), onde define o sujeito como sendo um lugar social constituído historicamente e marcado no discurso, afastando-se da noção logocêntrica de indivíduo empírico. Ironizando essa noção do sujeito racional, senhor de si, Pêcheux (2009, p. 144) relembra o conto fantástico do ba- 
rão de Münchhausen fazendoreferência à cena fantástica em que o barão se eleva "nos ares puxando-se pelos próprios cabelos". Um homem social, não pode se erguer pelos "próprios cabelos", já que vive em relação com outros homens, que com ele, são convocados a se tornarem sujeitos.

Nessa perspectiva, o conceito de sujeito corresponde "a certo lugar no interior de uma formação social dada (PÊCHEUX, 2009, p. 7). Esse lugar é constituído pela sociedade e pela ideologia que a determina e é interpretado (ou antecipado) por outros sujeitos a partir do que denominou de formações imaginárias, as quais representariam o lugar de sujeito no processo discursivo. São as formações imaginárias que nos permitem reconhecer o lugar social do professor, do patrão, do filho, do chefe de Estado, do missionário, do artista, do revolucionário. Assim começa a se delinear uma concepção de sujeito inscrito no discurso, que produz e é produzido por efeitos de sentidos, daí sua relação com a linguagem. Como o efeito Münchhausen, o sujeito não se sustenta sozinho, ele vive em sociedade, por isso não é origem dos sentidos que produz, visto que, por meio do discurso, há a interpelação ideológica dos indivíduos em sujeitos. Essa interpelação, afirmam Pêcheux e Fuchs (1997), é recalcada no inconsciente. A ideologia recalcada no inconsciente é o ponto chave da Análise do Discurso (AD), visto que explica por que uma palavra ou expressão adquire sentidos distintos para distintos enunciadores. Isso ocorre em virtude da inscrição dos sujeitos em diferentes formações discursivas que, segundo Pêcheux (2009), representam na linguagem as formações ideológicas responsáveis pela constituição da subjetividade. A formação discursiva (FD) é o que determina o que pode e deve ser dito em determinada conjuntura. Logo, é o aspecto ideológico da linguagem que permite o surgimento de sentidos possíveis ao invés de um único sentido. Assim, imagem e palavra já carregam em si a possibilidade de abrigar diferentes interpretações.

Para explicar a articulação da tríade conceitual da AD, a ideologia, a linguagem e o inconsciente, partimos da reformulação do nó borromeano do psicanalista Jaquecs Lacan feita por Ferreira (2010, p. 24). A autora explica que, para Lacan, o nó borromeano ligaria a tríade do inconsciente real-simbólico-imaginário através de um laço indissociável, que não poderia manter a interligação constitutiva das partes caso viesse a romper um de seus nós. O mesmo ela observa acontecer com a noção de sujeito na Análise de Dis- 
curso. O sujeito discursivo é constituído pela linguagem, pela ideologia e pelo inconsciente ao mesmo tempo, a representação figurativa do nó borromeano apresenta o sujeito no lugar de entremeio dessas noções. Ainda que esses conceitos já não sejam formulados do mesmo modo que no início da $\mathrm{AD}$, sua constituição mútua se preserva e aponta caminhos para uma teoria materialista dos sentidos, que faz da materialidade significante matéria histórica e, assim, simbólica. É nesses termos que se entende a linguagem no campo do discurso. Esta é apropriada pela AD contrariando a noção da língua sistêmica elaborada na linguística. Na ótica discursiva, a linguagem opera pela descontinuidade de sua estrutura, abrigando o equívoco, a opacidade, a ambiguidade e até mesmo o non-sens em sua estrutura.

É o simbólico, portanto, que liga os campos da linguagem, do materialismo histórico e da psicanálise. Em termos lacanianos, o simbólico é o que torna possível a expressão do imaginário, ou seja, é o que produz o efeito de "realidade" à existência do sujeito. Recuperando a paráfrase althusseriana de Kant de que "o homem é por natureza um animal ideológico" (ALTHUSSER, 1992, p. 94), vê-se que o aspecto "natural” da interpelação ideológica diz respeito à impossibilidade do sujeito significar, proceder discursivamente, senão pela ideologia. No campo simbólico é onde o sujeito pode significar, é o meio que ele tem para significar e significar-se. A ideologia como determinação simbólica é aquela que produz o imaginário necessário à simbolização, tal qual explica Orlandi (1996b, p. 65): “a ideologia será percebida como o processo de produção de um imaginário, isto é, produção de uma interpretação particular que apareceria, no entanto, como a interpretação necessária e que atribui sentidos fixos às palavras, em um contexto histórico dado" Esse imaginário recalcado no inconsciente apaga sua própria constituição para o sujeito, causando o efeito de transparência da linguagem, de que os sentidos são únicos e evidentes. Portanto, não há como escapar da ideologia, porque não há como escapar da história e do sentido. O homem é, assim, um animal simbólico.

Retomando a figura do nó borromeado reformulado por Ferreira (2010), entendemos que seja importante assinalar o elo que une os conceitos fundadores da noção de sujeito, visto que tanto a linguagem, quanto a ideologia aliada à história e ao inconsciente apontam para esta noção: a noção de simbólico. Assim, faz-se necessária uma nova reformulação: 


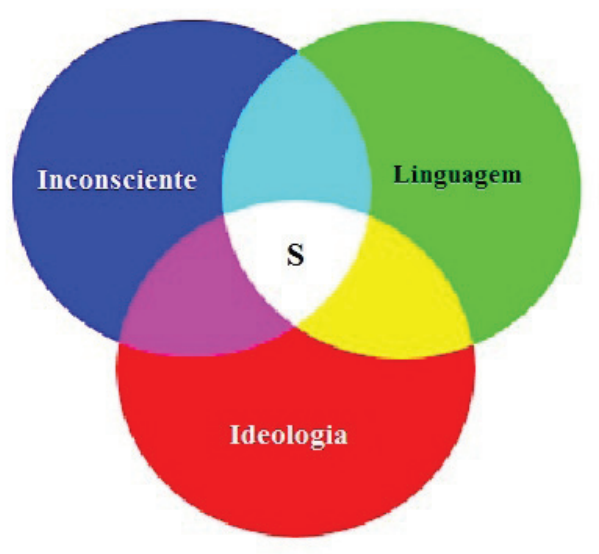

Essa versão representa o nó borromeano pelas cores primárias e suas composições para mostrar como a articulação entre os conceitos afeta sua constituição original; por exemplo, o inconsciente ao entrar em contato com a ideologia já sofre alteração em sua constituição, assim como com a linguagem. A relação mútua entre os três conceitos transforma-os ao mesmo tempo, o que é representado pela cor branca que indica a união das três cores primárias. Assim como no sistema cromático, em que as cores ao entrarem em contato se modificam, também ocorre com as noções fundamentais da $\mathrm{AD}$. E sua união está longe de ser mero acréscimo, mas uma verdadeira transformação. Além disso, apenas a letra $S$ foi deixada no centro, mostrando que, se sujeito e sentido se constituem mutuamente "pela articulação da língua com a história" (ORLANDI, 2008, p. 99), o núcleo central dessa injunção pode ser tanto o sujeito quanto o sentido, ou ainda, o simbólico, todos representados pela mesma letra S. A partir dessa incursão pelas noções bases da teoria que sustenta a análise, passamos a discutir a constituição do sujeito produtor do livro de imagens e do processo discursivo de escrita desse livro.

\section{O SUJEITO-ARTISTA VISUAL E SUA ESCRITA}

A constituição ideológica do sujeito-autor de livros de imagens e seu recalque pelo inconsciente explica o modo como este interpreta o mundo, 
representando-o e recriando-o por meio de um imaginário necessário. Com formas e tons, o sujeito produtor de imagens produz discursos que simulam ou mesmo distorcem a imagem visível de todo dia. O modo como materializa a dispersão discursiva o inscreve na ordem do estético e do poético próprios da formação ideológica das Artes que engloba as formas sensíveis de discursividade como a dança, a música, o teatro, o cinema, a literatura, as artes visuais, sendo esta última a que identifica o sujeito com seu modo de materializar o discurso. Portanto, o sujeito que produz (enuncia) a imagem artística identifica-se particularmente com a formação discursiva das artes visuais regulada por uma Forma-sujeito que prima pelo saber sensível no manejo do significante visual.

A Forma-sujeito ou Sujeito do Saber é, segundo Pêcheux (2009), o meio pelo qual o enunciador se identifica com a formação discursiva que o constitui, é o que dá ao sujeito sua ilusão de unidade e completude. Indursky (2008) assinala ainda que a Forma-sujeito (FS) é que regula os saberes no interior da FD, interditando os sentidos que não lhe são admitidos. Portanto, pela identificação com a FS é que se pode notar o pertencimento ou não a um domínio de saber específico, isto é, à determinada FD. No caso das artes visuais, de acordo com Hauser (1978), os saberes que lhe são próprios dizem respeito à originalidade, sendo esse elemento o que especifica a linguagem da arte. $\mathrm{O}$ autor explica da seguinte forma:

A obra de arte é simultaneamente forma e conteúdo, afirmação e decepção, jogo e revelação, natural, artificial, intencional e sem finalidade, dentro e fora da história, pessoal e suprapessoal. Todavia, nenhuma destas características parece ter um significado tão universal como o da originalidade; uma obra de arte deve exprimir a sua própria concepção do mundo nova e específica se tiver de ter algum valor em si própria, e na verdade alguma qualidade estética.

(HAUSER, 1978, p. 407) 
Assim, toda obra de arte possui uma "linguagem" própria, cada artista visual possui seu modo de enunciar que é dado pelo efeito de originalidade produzido em sua criação visual. Hauser (1978) dirá que cada artista possui seu próprio "dicionário", que pode ser dado pela combinação singular de cores (por ex., há pintores que apresentam uma palheta de cores particular), pela forma do traço ou pelo modo de produzir texturas.

No campo teórico da Análise de Discurso, o discurso da arte é analisado por Neckel (2010) que o classifica como lúdico e polêmico, conforme a tipologia estabelecida por Orlandi (1996a). O caráter lúdico se refere ao fato do artista visual projetar na imagem os discursos sem sobreposições, buscando o jogo das formas e das cores resultando em uma polissemia aberta. A matéria textual é explorada sem que um sentido venha a se impor como predominante. Sendo polêmico, o discurso da arte aponta as divergências em seu campo, onde os sentidos estão em disputa permanente, mas não escolhe um dos lados, todos os saberes convivem ou mesmo disputam espaço sem se sobreporem uns aos outros, o que torna o sujeito artista visual, na definição de Campos (2010), um "sujeito à deriva”. Esse aspecto do discurso artístico resulta do gesto de interpretação do artista visual que opera, segundo Neckel (2010, p. 135), por meio de um "dispositivo sensível e analítico". Os saberes da FD da arte se constituem, portanto, em torno da estética e da poética. Estética é um termo vindo do grego aísthesis, que significa sensação e sentimento (ROSENFIELD, 2006, p. 07), e representa um campo da filosofia que analisa o complexo de sensações e dos sentimentos nas obras artísticas. Esses sentimentos são materializados na textualidade do discurso artístico e aparecem visivelmente nas cores, no traço, na textura da obra visual (seja uma pintura ou escultura). Esses recursos visuais correspondem ao caráter poético da produção estética, ou seja, a poética nas artes visuais advém de sua própria matéria física, como explica Cattani (2007, p. 12):

A poética pode ser considerada como tudo o que constitui a obra em si mesma, a partir do momento de sua instauração. Trata-se da obra na sua fisicalidade própria, com suas formas, materiais, técnicas, suportes, ou 
seja, todos os elementos utilizados na sua constituição pelo artista. Mas, trata-se também de seus múltiplos sentidos e significados, os quais escapam, em parte, ao desejo, à intenção e até mesmo ao controle do seu criador. (...) é a obra em sua trajetória própria que a leva, através do tempo e do espaço, a acumular sentidos novos e plurais.

Ambas as instâncias, estética e poética, implicam a relação com o belo na arte. A bela imagem é perseguida por meio de novas cores, tonalidades, combinação de traços, textura etc. Durante a produção dos livros de imagem, é possível obter um espaço de criação que, segundo Colomer (1996, p. 31), configura-se como um campo de experimentação da criação literária e artística. Essa observação é corroborada pelos ilustradores André Neves e Angela Lago como se pode ver nas sequências discursivas (SD) verbais abaixo:

SD verbal 01:

Os ilustradores contemporâneos inovam a cada dia na tentativa de construir, dentro do livro, arte.

(NEVES, apud OLIVEIRA, 2008, p. 169).

SD verbal 02:

Mas, afinal, o que é um livro de imagem? Como o códice no seu frescor, um lugar para descobrir e explorar novas possibilidades narrativas. "Um campo de experimentação", nos diz Teresa Colomer, no seu artigo "El álbum y el texto".

$\left(\right.$ LAGO, 2010) ${ }^{1}$

A partir dessas SDs é possível perceber, na fala do sujeito-ilustrador, o discurso das artes visuais sobre a "originalidade" artística, visto que é pela

1 Retirado de http://www.angela-lago.com.br/codice.html. Acesso em: 10 abr. 2010. 
experimentação que se atinge esse efeito no dizer visual. A criação estética por meio da experimentação se constitui em torno de novos materiais e combinações que possibilitam "novas narrativas" ou novas formas de textualização. Essa busca pelo novo é necessária para se atingir o efeito de originalidade e autenticidade exigido pela Forma-sujeito da FD das artes visuais. Essa busca coloca-se até mesmo como um incômodo para o artista visual, como observa Csikszentmihalyi (1998). A necessidade de inovar no ato criativo é definida no campo da arte como o "fluir do artista": "para o artista, a motivação que o leva ao fluir é a sedução da arte, o desejo de fazer arte, de expressar-se na linguagem da arte" (CSIKSZENTMIHALYI, 1998, p.43), linguagem esta que já sabemos ser original.

Seduzido pela arte, o artista visual anseia por novas descobertas, é o que Angela Lago faz na obra Cena de Rua ao inovar no enquadramento de sua narrativa visual. Normalmente, a dobra formada pela união das páginas representa um empecilho para qualquer ilustrador ou escritor de narrativas visuais, visto que a dobra já representa uma divisão. A imagem no centro seria então cortada ao meio. Para fazer aflorar "novas possibilidades narrativas" (LAGO, 1995), Angela busca nessa obra resolver o problema da junção central das páginas, considerando a bidimensionalidade do objeto livro. Csikszentmihalyi (1998, p. 105) afirma que: "Em certas circunstâncias, o processo criativo começa com a meta de resolver um problema que alguém planta na pessoa ou que é sugerido pelo estado em que se encontra a área". Segundo Lago (1995), usando "a dobra do meio do livro e a curvatura da folha aberta como recurso podemos enfatizar perspectivas, acentuar movimentos, assinalar aspectos da narrativa”. Em Cena de Rua, Angela Lago formulou a imagem de modo que a dobra da página coincidisse com as articulações do menino, as quais, no movimento de leitura do livro, fazem a imagem plana se deslocar, dando movimentação ao personagem, causando a impressão de que a personagem se move entre os carros (imagem 02). 


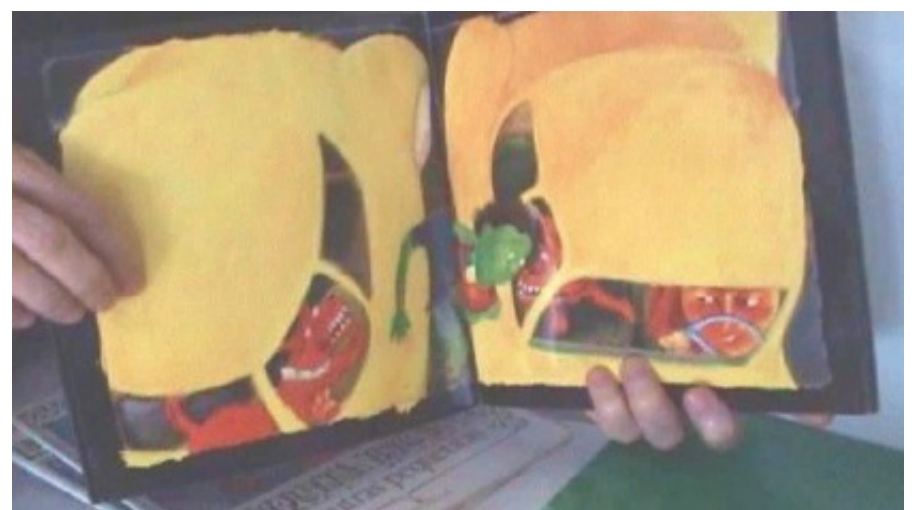

Imagem 02: Angela Lago mostra o efeito da dobradura no movimento das páginas (ARAÚJO, 2010, p.71)

O movimento causado por essa dobra da página faz com que as laterais se fechem e encurralem, ainda mais, o menino entre os carros, produzindo o efeito de sufocamento, detenção, ou mesmo, supressão do garoto.

Não só o trabalho de enquadramento, mas a exploração dos materiais e das técnicas de ilustração explicitam o caráter artístico do funcionamento dessa discursividade. A inquietação operada pelo desejo da inovação e perfeição estética envolve o escritor desse tipo de livro mais que o conteúdo de sua obra. Não é o que dizer pela imagem o importante, mas o como dizer pela imagem, é assim que entendo o funcionamento do discurso no livro de imagem como uma construção da discursividade artística. O que estou propondo fica mais compreensível a partir das sequências discursivas verbais a seguir:

SD verbal 03:

$\mathrm{Na}$ verdade, acho que limites e dificuldades funcionam como estímulo. Ando querendo aprender a confiar cada vez mais nas possibilidades abertas por eles, inclusive nas abertas pelos meus próprios limites e dificuldades. E também nos erros. Os erros, nos trabalhos de criação, levam a caminhos quase sempre mais 
interessantes que os meros acertos. Essa é, pelo menos, a mais confortável das minhas convicções.

(LAGO, 1995) ${ }^{2}$.

SD verbal 04:

Tem coisas que eu gosto muito de fazer que não é pela questão da narrativa, é pela questão plástica. Eu gosto de trabalhar com detalhes. Eu não gosto de colocar um fundo por um fundo, isso não sei se vou mudar, pelo prazer que tenho em executar. Eu gosto de descobrir outras possibilidades com a tinta. Às vezes, demora para secar, às vezes não dá certo. Eu gosto de experimentar, usar tudo que me vem à cabeça. Às vezes, eu não consigo repetir alguns resultados. Mas a tentativa me surpreende com outros resultados. Gosto disso. Às vezes, demoro para encontrar e nesse processo vou descobrindo outras coisas. Meu trabalho é bastante experimental. (NEVES apud ARAÚJO, 2010).

A experimentação é uma necessidade do processo criativo, cujo objetivo é produzir o efeito de originalidade ${ }^{3}$. Esse aspecto da constituição do sujeito produtor do livro de imagens o identifica com os saberes das artes visuais, mostrando que é esta FD que o determina. Essa identificação fica visível através das exposições dos trabalhos. Nas exposições de ilustradores, os esboços dos desenhos dos livros são expostos em suportes nas paredes, como se fossem verdadeiras obras de arte, é o que podemos ver na imagem 03 logo a seguir:

2 Texto de 1995, Belo Horizonte. Disponível em: http://www.angela-lago.com.br/palestra. html. Acesso em: 07 jul. 2010

3 A originalidade é tomada como um efeito, visto que, em $\mathrm{AD}$, consideram-se os sentidos historicamente constituídos. É como observa Hauser (1978, p. 411): “Todo artista fala a linguagem de seus predecessores, e algum tempo decorre até que comece a falar com sua própria voz", isto é, o discurso artístico não surge no sujeito enunciador, ele já está lá, e é a partir do que já está posto que se cria o novo, como um efeito do já dito, como uma reformulação ou reatualização do dizer. 


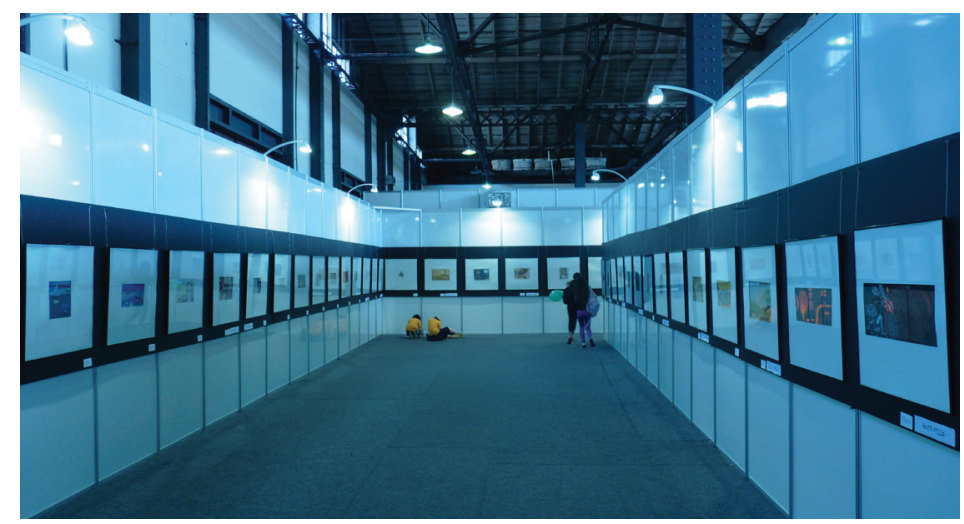

Imagem 03: Originais de ilustração expostos na exposição da VII Traçando histórias, em Porto Alegre, novembro de 2010. Ao fundo crianças fazem anotações sobre as obras para trabalho escolar. ${ }^{4}$

Como ser simbólico inscrito na materialidade da narrativa visual, o produtor de imagens em sequência apresenta uma constituição complexa, visto que, além dos sentidos que o inscrevem em determinado lugar social, o do ilustrador, este é um sujeito constituído por saberes de distintas ordens discursivas. Ao traçar a historicidade do livro de imagens, entendemos que o sujeito por trás da imagem narrativa, ou ainda, literária, tem origem no lugar discursivo de ilustrador, que representa um espaço de discursividade constituído pela FD das artes visuais ${ }^{5}$. O sujeito-ilustrador se identifica com a Forma-sujeito dessa FD (ver esquema abaixo). O conceito de lugar discursivo (LD) é desenvolvido por Dorneles (2005) como sendo a materialização

4 Fotografia de nossa autoria. A Exposição da VII Traçando Histórias reuniu trabalhos de ilustradores brasileiros renomados, como André Neves, Rosinha Campos, Nelson Cruz, entre outros. Além disso, o evento fez uma homenagem especial para Angela Lago e Eva Furnari pelos 30 anos de carreira, por sua dedicação à arte da ilustração de livros infantis.

5 Vale ressaltar que o sujeito empírico ilustrador não se confunde com o sujeito discursivo, visto que inserir o ilustrador na FD das artes visuais não significa que os ilustradores sejam formados, obrigatoriamente, em cursos de Artes Visuais ou Artes Plásticas. Alguns receberam sua instrução formal em escolas de Belas Artes, como Rui Oliveira, entretanto muitos são autodidatas, como Nelson Cruz e André Neves, outros se especializam em designer, arquitetura, comunicação. Apesar da diferença na instrução formal, no âmbito do discurso, esses ilustradores constituem-se pelo mesmo domínio de saber. 
discursiva do lugar social, aquele formado pela representação imaginária do sujeito na sociedade. O lugar social configura o espaço de enunciação do sujeito, dando legitimidade ao seu dizer, já o lugar discursivo é definido pela autora (DORNELES, 2005, p. 119) como sendo "estrutura, pré-construído, realidade com a qual o sujeito se relaciona e a partir do que se constitui em diferentes posições".

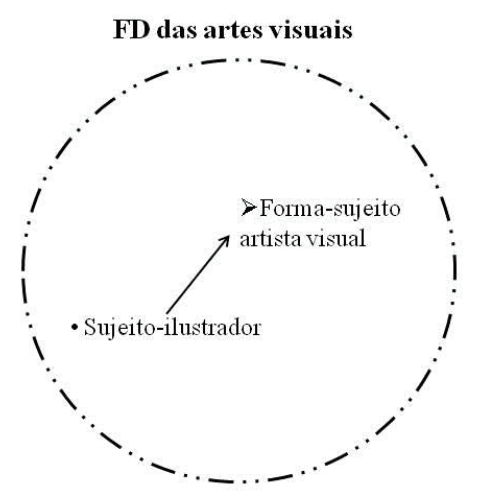

O lugar do ilustrador é discursivizado de modo diferente daquele do pintor na sociedade. Mesmo que utilizem técnicas semelhantes, as funções são distintas, uma vez que um produz a imagem para ser reproduzida em um livro impresso e comercializável e o outro a produz para ser diretamente contemplada. Nas exposições como a da imagem 03, percebe-se que, ao tirar a imagem do livro, ela ganha um novo significado, pois como observa Oliveira (2008), uma das diferenças entre o pintor e o ilustrador é o suporte e a circulação de suas produções visuais. $\mathrm{O}$ ilustrador produz suas materialidades visuais em livro para serem reproduzidas e lidas em uma sequência. Dessa forma, o "espectador" (leitor) dessas imagens não tem acesso aos originais como no caso da pintura que expõe diretamente a obra a seus espectadores. Quando o livro é exposto, o efeito narrativo se perde e o que resta é a contemplação da estética visual daquelas páginas imóveis, produzindo o efeito de obras de arte de fato. O efeito estético das duas produções são diferentes, o que indica que o ilustrador inscreve-se em um lugar específico, o que faz com que se relacione de modo singular com a FD das artes visuais, tomando uma posição diferente da de outros artistas visuais (como o pintor 
e o escultor) com relação à Forma-Sujeito dessa FD. Essa tomada de posição diferenciada do ilustrador lhe permite incorporar saberes de outras FDs, já que este mobiliza imagens em sequência, os domínios de saber dos HQs, das animações e do cinema, são igualmente convocados.

As posições que toma o sujeito dentro da FD das artes visuais dizem respeito ao modo próprio de enunciação que se faz através de uma sucessão de imagens. As imagens postas em sequência indicam uma temporalidade que é representada por sua disposição espacial. Essa relação espaço/tempo, típica da estrutura narrativa, convida o espectador a produzir um efeito narrativo durante a leitura das imagens, esse efeito é o que dá literalidade ao livro de imagens, fazendo do artista visual um escritor. Essa constituição heterogênea do espaço enunciativo da ilustração faz ressoar as observações de Pêcheux (2009, p. 314) a propósito da noção de formação discursiva, assinalando que: "o dispositivo da FD está em relação paradoxal com seu "exterior": uma FD não é um espaço estrutural fechado, pois é constantemente "invadida" por elementos que vêm de outro lugar (isto é, de outras FD) que se repetem nela, fornecendo-lhe suas evidências fundamentais (por exemplo sob forma de "pré-construídos" e de "discursos transversos")".

Essa revisitação da noção de FD torna possível a análise do lugar discursivo da ilustração dentro da FD das artes visuais, visto que sua constituição nada homogênea faz circular saberes de outras FDs, como os da FD literária, que juntamente com os saberes internos sobre técnicas de reprodução de imagens e de formatação do espaço visual do livro, afetam o sujeito, cindindo-o em diferentes posições-sujeito, como ilustra o esquema a seguir:

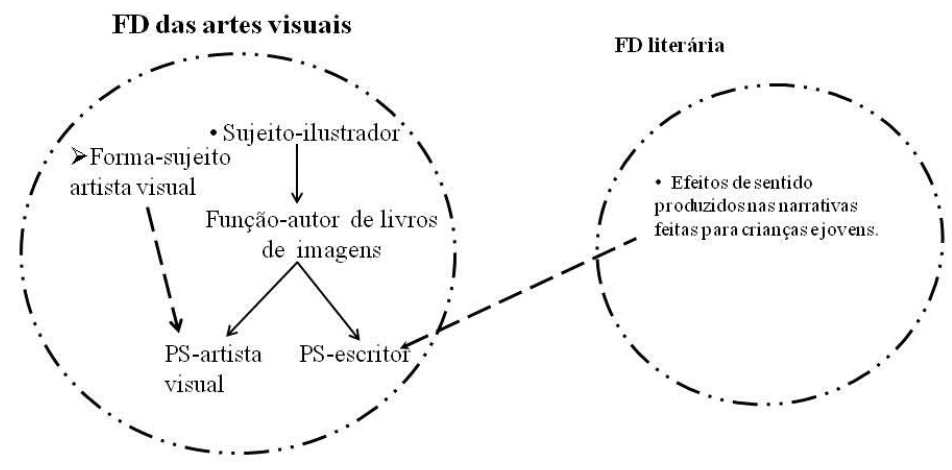


A noção de posição-sujeito (PS) na AD diz respeito ao modo específico em que o sujeito se inscreve na FD que o interpela, no caso das artes visuais, o sujeito-ilustrador pode abrigar discursos que vêm de fora, constituindo posições enunciativas diferentes dentro da FD de origem, ou seja, produzindo modos diferentes de formular, diferentes gestos de escrita, como é o caso da sucessão de imagens. Sendo assim, Courtine (1981, p. 43) ${ }^{6}$ formula a noção de posição-sujeito (PS) do seguinte modo: "Nós concebemos então uma posição de sujeito como uma relação determinada que se estabelece numa formulação entre um sujeito enunciador e o sujeito de saber de uma FD dada”. Posição-sujeito é, assim, um desdobramento da Forma-sujeito, como propõe Pêcheux (2009, p. 160), que se origina pela "construção da exterioridade no próprio interior do sujeito".

Nos domínios da FD das artes visuais, os saberes que regulam a FD e o sujeito do saber reúnem as habilidades no uso das técnicas de representação visual, o que o sujeito-escritor de livros de imagens mantém assumindo a posição de artista visual. Por outro lado, assume a posição-sujeito de escritor ao produzir o efeito narrativo, o que revela a incorporação dos saberes da FD literária. A interpelação da FD das artes visuais é que determina o modo como o ilustrador se relaciona com o domínio literário. Por sua constituição ideológica, o ilustrador não se reconhece como escritor, mas como artista visual. É o que se pode observar por meio da sequência discursiva (SD) verbal retirada de uma entrevista com o ilustrador André Neves:

\section{SD verbal 05:}

Outra coisa que me faz criar um livro de imagem é tentar tirar dele as palavras, escrever, é pelo simples fato de eu ser um artista visual. A minha palavra vem da imagem e nunca foi ao contrário. Eu entrei nesse trabalho, nessa profissão, como artista visual, e não como artista verbal. Foi a imagem que me levou a criar palavras.

(Neves apud ARAÚJO, 2010, p. 63).

\footnotetext{
6 « Nous concevons donc une position de sujet comme un rapport détérminé qui sétablit dans une formulation entre un sujet énonciateur et le sujet de savoir d'une FD donnée » (Courtine, 1981, p. 43, tradução nossa).
} 
Considerando a SD acima, pode-se compreender que é pelo viés da PS de artista visual que o produtor de imagens se relaciona com a FD literária, já que suas palavras são as próprias imagens. O sujeito se identifica fortemente com a posição-sujeito de artista visual que é aquela que o constitui enquanto sujeito, esta posição é, portanto, o recobrimento da Forma-sujeito da FD das artes visuais. Já a posição-sujeito escritor surge por uma contra-identificação (PÊCHEUX, 2009) à Forma-sujeito que o constitui, e faz com que o ilustrador tenha que aliar as técnicas de representação visual às técnicas de expressão da temporalidade e da espacialidade, próprios da estrutura narrativa. É a habilidade em representar e criar artisticamente imagens que faz o sujeito-artista visual ocupar o lugar de ilustrador e, a partir da aproximação com a literatura infantil e juvenil, assumir a posição de escritor dos próprios livros. A imagem é que coloca o artista visual na posição de escritor, pois é na imagem e pela imagem que ele se reconhece enquanto sujeito, parafraseando o teórico da enunciação Émile Benvensite.

Como é possível perceber, o sujeito-artista visual ocupando o lugar discursivo de ilustrador, na função de escritor de imagem, é interpelado pelos saberes da arte visual, entretanto apresenta como seu outro eu a literatura, o que também faz parte da formação ideológica das artes, imbuída da estética e da poética, assim como do efeito de originalidade. No âmbito da arte visual, há um deslocamento da própria definição de literatura que deixa de ser a arte de lidar com as palavras, para ser a arte de pintar com poesia a imagem. Rui de Oliveira dirá que há uma "literatura visual" (2008, p. 84), considerando as imagens poéticas e seus poetas, artistas visuais. Portanto, a literatura aclamada no lugar discursivo da ilustração está fortemente imbricada com o processo discursivo da produção de imagens, criando novos gestos de escrita.

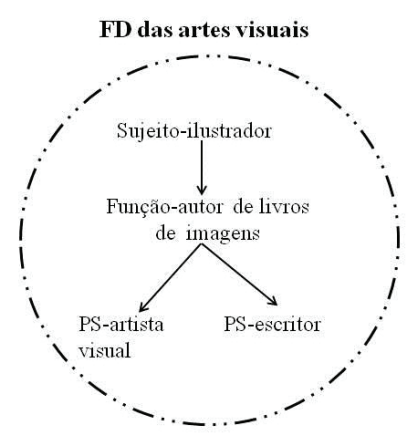


Essas duas posições-sujeito se imbricam na função-autor de narrativas visuais. Esse atravessamento constitui um sujeito cindido que opera no entremeio das formações discursivas das artes visuais e literária. O lugar fronteiriço onde reside faz funcionar esse sujeito produtor de imagens, ao mesmo tempo, como artista visual e escritor. Esse imbricamento de posições-sujeito na configuração do lugar discursivo do ilustrador determina o modo de constituição da função-autor do livro de imagens, e consequentemente do processo criativo desta obra. Da mesma forma que a definição de sujeito, o autor tratado na perspectiva do discurso não corresponde a um indivíduo de carne e osso, mas a uma construção discursiva. A AD parte da definição foucaultiana de autor como "o princípio de uma certa unidade de escrita" (FOUCAULT, 1992, p. 53), ou seja, “o autor, não entendido, é claro, como indivíduo falante que pronunciou ou escreveu um texto, mas como princípio de agrupamento do discurso, como unidade e origem de suas significações, como foco de sua coerência" (FOUCAULT, 1996, p. 26). Esse princípio organizador da dispersão discursiva que confere aos textos um aspecto uniforme, de um todo coerente, é a função-autor. Para a AD, esse conceito substitui o ser biológico autor, o que é essencial aos estudos sobre texto enquanto materialidade discursiva. Segundo Orlandi (1996b, p. 69), "a função-autor se realiza toda vez que o produtor da linguagem se representa na origem, produzindo um texto com unidade, coerência, progressão, não-contradição e fim”. A função-autor se torna o princípio de organização interna do texto (da textualidade), da dispersão do sujeito discursivo que se divide em diferentes posições-sujeito no interior de um mesmo texto. Cabe à função-autor organizar essas posições no texto de modo a evitar a incoerência. O autor é, portanto, a função da noção de sujeito responsável por organizar o sentido e por produzir o efeito de unidade do texto.

Ao desenvolver a noção de função-autor no tratamento do livro de imagens, é necessário retomar a característica heterogênea de constituição do sujeito-produtor do livro de imagens que se identifica com os saberes das artes visuais, da literatura, e de outros campos discursivos como o cinema e os HQs. Retomando a reflexão sobre a divisão do sujeito produtor da textualidade visual, percebemos o desmembramento da função-autor em duas posições-sujeito: a do artista visual (que trabalha a imagem em sua forma 
estética, experimentado diversas técnicas) e a do escritor (autor de uma narrativa, buscando por meio da linguagem visual produzir certos efeitos de sentido). Assim, o sujeito se divide entre a especialidade na produção de imagens e seu desafio que é o de se colocar como escritor, ou seja, produtor de uma narrativa. Porém a materialidade dessa narrativa é própria de sua especialidade, é visual. O caso, portanto, é diferente da função-autor de ilustrações que produz imagem partindo de um texto verbal. Nas obras visuais, a imagem é o próprio texto. A linguagem é outra, o que causa o imbricamento dessas duas posições-sujeito. Não há como separar, ora ser artista visual, ora escritor, o sujeito se torna híbrido, pois uma atividade depende da outra.

Logo, as posições-sujeito imbricadas no texto visual, ao invés de se confrontarem em busca de dominância, elas tornam-se aliadas na produção de sentidos. O livro de imagens Espelho, da ilustradora tcheca Suzy Lee (2010), dá visibilidade a esse processo discursivo. Não se pode definir se é o jogo criado com as páginas do livro como efeito de uma monotipia que permite a criação de uma narrativa, cujo efeito se dá pelas imagens refletidas no espelho, ou é a história da relação de uma menina solitária com seu reflexo no espelho que inspira a criação estética. Mas o que há de material é o livro, cuja produção relaciona de tal forma sintaxe visual e sintaxe narrativa que não podemos distingui-las ou sobrepô-las. A obra começa com a imagem de uma menina no canto da página em branco, em outra página a garota se assusta ao ver uma duplicação de sua imagem. Então, passa a produzir movimentos que são repetidos na página ao lado pela imagem que copia todos os seus movimentos, produzindo o efeito de reflexo no espelho ${ }^{7}$. Assim, em uma página temos a menina e na página ao lado o seu reflexo, produzindo o efeito de um espelho.

7 O slide show, trazido no site oficial da ilustradora, mostra os momentos iniciais de confronto da menina com seu suposto reflexo, disponível em http://www.suzyleebooks.com/ books/mirror/slide/mirror.htm. Acesso em: 16 fev. 2014 


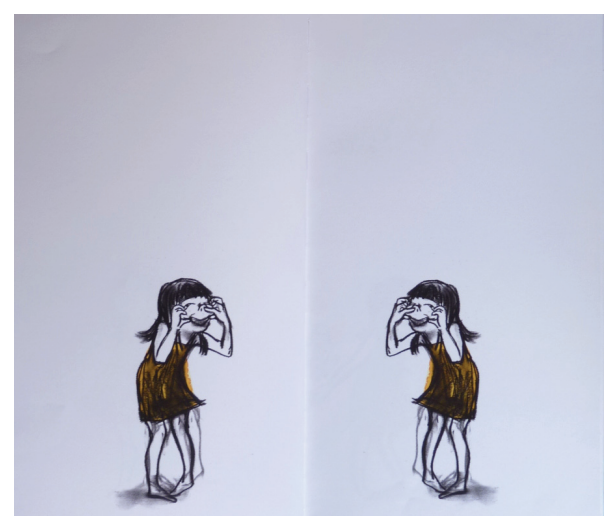

Imagem 04: Páginas 14 e 15 do livro Espelho, de Suzy Lee, Editora Cosacnaify (2010).

A função-autor representa o sentimento de satisfação da menina solitária por ter encontrado uma amiga com cores e tintas espalhadas pelo plano da página como se fosse uma reduplicação da imagem na dobra da folha (efeito da técnica de monotipia).

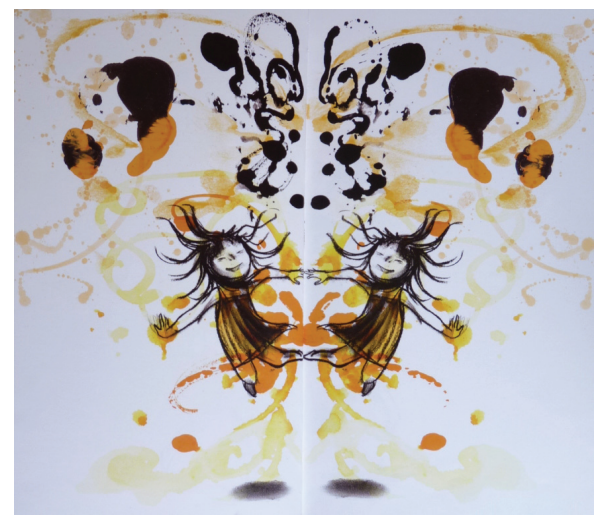

Imagem 05: Páginas 20 e 21 do livro Espelho, de Suzy Lee, Editora Cosacnaify (2010).

O jogo com as imagens da personagem segue até que a representação visual da menina e de seu reflexo são incorporados pela união das páginas, produzindo o efeito de que as "meninas" entram no livro, ou então, no que o livro representa como espelho. As imagens vão se fundindo e 
chegam a formar uma só imagem com dois olhos, dois braços, duas pernas, e um rosto que parece estar sorrindo (imagens 06 e 07). A produção dessa terceira imagem significa na escrita desse texto visual, mostrando uma fusão entre a menina e seu reflexo no espelho que chega a produzir uma terceira "menina".

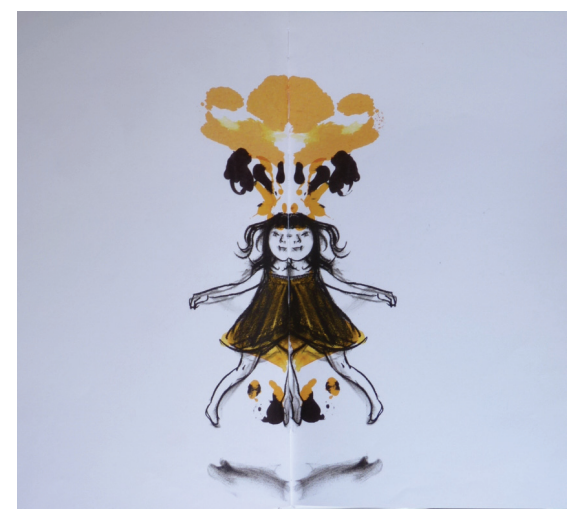

Imagem 06: Páginas 22 e 23 do livro Espelho, de Suzy Lee, Editora Cosacnaify (2010).

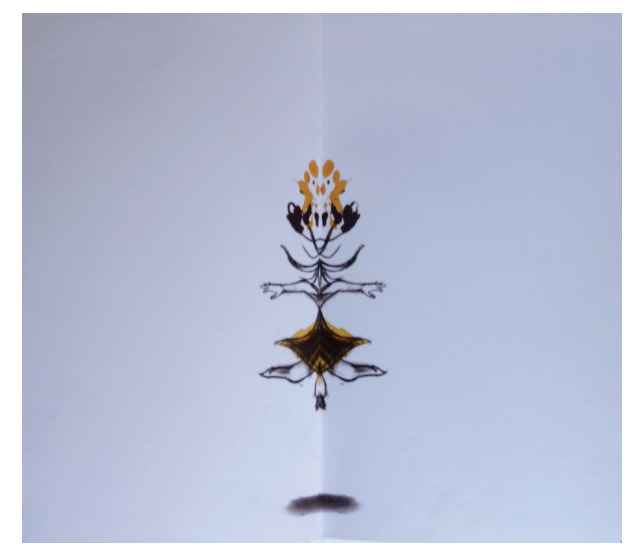

Imagem 07: Páginas 24 e 25 do livro Espelho, de Suzy Lee, Editora Cosacnaify (2010). 
Na página seguinte, vislumbramos apenas uma página em branco. Onde estariam as meninas? Ou a menina e seu reflexo? Em outra página, as imagens surgem novamente, com uma diferença, cada uma dança a seu modo. Esse descompasso causa a ira da menina solitária que não se conforma com a autonomia de sua imagem refletida. Ela, então, empurra a imagem quebrando o espelho. Com essa atitude, ela volta à solidão, sentando-se na mesma posição em que a encontramos no início da narrativa. A representação pictórica do espelho somente é explicitada nesse momento de cólera da personagem (imagem 08). Nessas páginas, é quando se percebe mais claramente se tratar de um espelho e não apenas de um outro plano da página: a imagem separada da página, os pedaços de vidro e a reação da menina que parece se assustar com o barulho e os estilhaços de vidro no chão (imagem 09). Essa primeira representação dúbia de não distinguir claramente entre a personagem e seu reflexo também é um recurso artístico e autoral que produz um efeito na narrativa, confunde o olhar do leitor, permitindo a interpretação de que a menina poderia ter mesmo encontrado alguém igual a ela até o momento de revelar que a outra menina era mesmo apenas um reflexo no espelho.

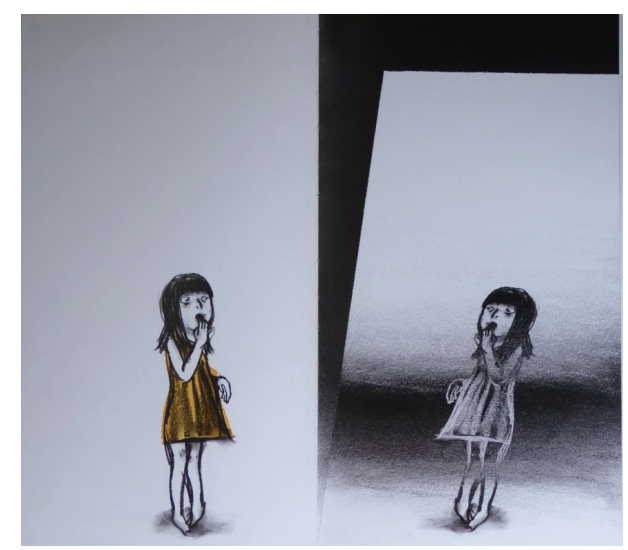

Imagem 08: Páginas 44 e 45 do livro Espelho, de Suzy Lee, Editora Cosacnaify (2010). 


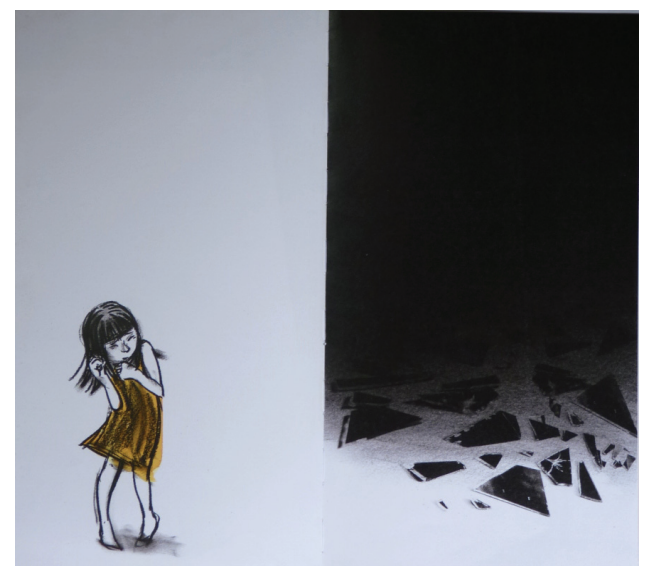

Imagem 09: Páginas 46 e 47 do livro Espelho, de Suzy Lee, Editora Cosacnaify (2010).

Se a função-autor se efetiva pelo imbricamento das posições-sujeito artista visual e escritor, a relação entre essas posições diz respeito ao surgimento de uma modalidade nova de escritor ou de artista visual no lugar discursivo de ilustrador: o sujeito-escritor de imagens. Os sentidos produzidos para a obra surgem da tensão entre essas duas posições-sujeito, a de escritor e de artista visual, sendo que uma afeta a constituição da outra produzindo um discurso literário próprio dessa interligação entre o literário e o visual. Desse modo, essas posições entram em jogo mutuamente numa relação de dependência, não há sucessão ou alternância, a criação literária e a criação artística visual se constroem simultaneamente.

Considerando o livro Espelho, de Susy Lee, não podemos afirmar que haveria uma narrativa antecipando a produção das imagens, que pudesse apenas ser "traduzida" por significantes visuais. Essa constituição ambígua do sujeito-autor do livro de imagem interfere no processo de escrita do livro de imagens, principalmente no que se refere aos aspectos da autoria como princípio de organização discursiva e de responsabilização do dizer. No texto verbal, esses aspectos se materializam por meio de recursos autorais que produzem o efeito de unidade e de fechamento do texto. Entretanto, entendo que os recursos autorais dos livros de imagens funcionam de modo diferente, como no caso do livro Espelho que acabamos de analisar, não há a dominância de uma única posição-sujeito, mas o imbricamento de duas, 
sem dominância. No texto visual, portanto, não se pode falar em "incoerência” por não haver o predomínio de uma única posição-sujeito. No livro de imagem, os recursos autorais funcionam de modo diferente, produzindo efeitos de unidade ao mesmo tempo em que produzem efeitos de dispersão.

\section{CONSIDERAÇÕES FINAIS}

Este artigo propôs uma discussão à luz da Análise do Discurso Francesa sobre os conceitos de escrita, linguagem, discurso, sujeito e autor, tendo em vista a especificidade do processo discursivo e criativo dos livros de imagem. Para compreendermos tal especificidade, foram necessárias algumas reformulações de ordem teórica, como a da noção de linguagem que passa a ser considerada materialidade significante, o que nos possibilita abordar o significante visual. Adotando a percepção materialista da linguagem, revemos a noção de escrita que, como vimos, não se reduz à linguagem verbal, podendo caracterizar a materialização do discurso pelo significante visual. Nessa direção também caminha o conceito de autor que não diz respeito apenas à organização interna do texto com o propósito de evitar a incoerência, mas também como processo discursivo que pode produzir efeitos de dispersão e de reciprocidade entre diferentes posições-sujeito.

Por meio das análises dos livros Espelho, de Suzy Lee (2010), e Cena de Rua, de Angela Lago (1994), foi possível compreender a singularidade do gesto de escrita do ilustrador na composição do livro de imagens. Entendemos que, a partir de sua constituição híbrida entre duas posições-sujeito, a do artista visual e a de escritor, o autor do livro produz uma textualidade original, que nos permite compreendê-la como uma escrita visual resultante de dois processos interligados: o processo discursivo de produção de sentidos e o processo criativo de produção da arte.

Comprovada a existência de uma escrita do significante visual, nos cabe questionar: teria essa escrita lugar no domínio da FD literária? Conforme nossa análise da constituição do sujeito produtor do livro de imagens, seu gesto de escrita identifica-se com a FD das Artes Visuais. No lugar discursivo de ilustrador, o sujeito-artista desenvolve um modo singular e original de 
enunciar a partir dos saberes que traz de outras FDs com as quais se aproxima, como a literatura, as histórias em quadrinhos e o cinema. Entretanto essa aproximação não opera um deslocamento para fora da FD das Artes Visuais. Isso significa que a escrita visual é possível para esse campo de saber e é nos limites desse domínio que pode operar deslocamentos de sentido de modo que as narrativas e a poesia possam ser investidas de formas e cores, permitindo-nos falar em uma "literatura visual". Portanto, a literatura é deslocada e ressignificada nas Artes Visuais, mas não no campo da FD literária, lá a escrita ainda é obra da arte com a palavra.

\section{REFERÊNCIAS}

ALTHUSSER, Louis. [1968]. Aparelhos Ideológicos de Estado: nota sobre os aparelhos ideológicos de estado (AIE). Tradução Walter José Evangelista e Maria Laura Viveiros de Castro. 6 ed. Rio de Janeiro: Edições Graal. Rio de Janeiro: Graal, 1992.

ARAÚJO, Hanna Talita G. P. Livros de imagens: três artistas narram seus processos de criação. 2010, 115f. Dissertação (Mestrado)- Universidade Estadual de Campinas, Campinas, SP, 2010.

BARTHES, Roland; MARTY, Eric. Oral/Escrito. In: Enciclopedia Einaudi. Porto: Imprensa Nacional Casa da Moeda, 11 v., 1987, p. 32-45.

CAMPOS, Luciene Jung de. Imagens à deriva: interlocuções entre a Arte, a Psicanálise e a Análise do Discurso. 2010, 157 f. Tese (Doutorado em Letras)Universidade Federal do Rio Grande do Sul, Programa de Pós-graduação em Letras. Porto Alegre,2010.

CATTANI, Icleia Borsa. Introdução. In: . (Org.) Mestiçagens na arte contemporânea. Porto Alegre: Editora UFRGS, 2007. 
COLOMER, Tereza. El álbum y el texto. Peonza - Revista de Literatura Infantil y Juvenil, n. 39, p. 27-31, dic. 1996.

CSIKSZENTMIHALYI, Mihaly. Creatividad. El fluir y la psicologia del descubrimento y la invención. Barcelona/Espanha: Paidos,1998.

COURTINE, Jean-Jaquecs. Analyse du discours politique. Langages, n.61, juin, 1981.

DORNELES, Elizabeth Fontoura. A dispersão do sujeito em lugares discursivos marcados. 2010. Tese (Doutorado em Letras)- Universidade Federal do Rio Grande do Sul, Programa de Pós-graduação em Letras. Porto Alegre, 2005.

FERREIRA, Maria Cristina Leandro. Análise do discurso e suas interfaces: o lugar do sujeito na trama do discurso. Organon. Porto Alegre, n. 48, v. 24, 2010, p. 17-34.

FOUCAULT, M. [1969]. O que é um autor?. 3 ed. Lisboa: Vega, 1992.

. [1970]. A ordem do discurso. 15 ed. São Paulo: EdiçõesLoyola, 1996.

HAUSER, Arnold. Teorias da Arte. 2 ed. [Título original: The philosophy of Art History]. Traduzido por F.G.E. Quintanilha. Lisboa: Editorial Presença, 1978.

HIGOUNET, Charles. História concisa da escrita. 10 ed. São Paulo: Parábola Editorial, 2003.

INDURSKY, Freda. Unicidade, desdobramento, fragmentação: a trajetória da noção de sujeito em Análise do Discurso. In: CAZARIN, E. A.; GRIGOLETO, E.; MITTMANN, S. Práticas discursivas e identitárias: sujeito e língua. Porto Alegre: Nova Prova, 2008.p. 9-33. 
. Estudos da linguagem: a leitura sob diferentes olhares teóricos. In: TFOUNI, Leda V. (Org.). Letramento, escrita e leitura: questões contemporâneas. Campinas, SP: Mercado de letras, 2010.p. 163-178.

LAGAZZI-RODRIGUES, Suzy. Recorte significante na memória. In: LEANDRO FERREIRA, M. et. al. (Org.). O Discurso na contemporaneidade: materialidades e fronteiras. Editora Claraluz: São Carlos, 2009. p. 65-78.

LAGO, Angela. Cena de Rua. Rio de Janeiro: RHJ, 1994.

. [1989]. Um livro de areia. Disponível em http://www.angela-lago. com.br/aulaAreia.html. Acesso em: 07 jul. 2010.

. [1995]. Depoimento. Disponível em http://www.angela-lago.com. br/palestra.html. Acesso em: 07 jul. 2010.

LEE, Suzy. Espelho. São Paulo: Cosacnaify, 2010.

MARTINS, Wilson. A palavra escrita: história do livro, da imprensa e da biblioteca. São Paulo: Editora Anhembi limitada, 1957.

NECKEL, Nádia R. M. Tessitura e Tecedura: movimentos de compreensão do discurso artístico no audiovisual. Campinas, 2010. Tese (Doutorado). Universidade Estadual de Campinas, Campinas, 2010.

OLIVEIRA, Rui de. Pelos Jardins Boboli. Reflexões sobre a arte de ilustrar livros para crianças e jovens. Rio de Janeiro: Nova Fronteira, 2008.

ORLANDI, E. P. [1987]. A linguagem e seu funcionamento: as formas do discurso. 4 ed. Campinas, São Paulo: Pontes, 1996a.

. Interpretação: autoria, leitura e efeitos do trabalho simbólico. Petrópolis: Vozes, 1996b. 
. Discurso e texto: formulação e circulação dos sentidos. 3 ed. São Paulo, Campinas: Pontes, 2008.

PÊCHEUX, Michel [1969]. Por uma análise automática do discurso. In: GADET, F. \& HAK, T. (Org.). Análise do discurso: uma introdução à obra de Michel Pêcheux. Campinas: Editora da UNICAMP, 1997. p. 61-162.

. [1975]. Semântica e discurso: uma crítica à afirmação do óbvio. 4 ed. Campinas, São Paulo: Editora da UNICAMP, 2009.

. [1983]. O papel da memória. In: ACHARD, P. et al. (Org.) Papel da memória. Tradução e introdução José Horta Nunes. Campinas: Pontes, 1999. p. 49-58.

PÊCHEUX, M.; FUCHS, C. [1975]. Por uma análise automática do discurso; atualização e perspectivas. In: GADET, F. \& HAK, T. (Org.). Análise do discurso: uma introdução à obra de Michel Pêcheux. Campinas: Editora da UNICAMP, 1997. p. 163-187.

ROSENFIELD, Kathrin H. Estética. Rio de Janeiro: Editora Zahar, 2006.

SAUSSURE, Ferdinand de [1916]. Curso de linguística geral. 27 ed. São Paulo: Cultrix, 2006. 